\title{
Commentary: Mapping a future for continuous-flow ventricular assist devices
}

\author{
Amit Iyengar, MD, MS, and Pavan Atluri, MD
}

\footnotetext{
From the Division of Cardiovascular Surgery, Department of Surgery, Hospital of the University of Pennsylvania, Philadelphia, Pa.

Disclosures: Authors have nothing to disclose with regard to commercial support.

Received for publication Feb 12, 2019; accepted for publication Feb 13, 2019; available ahead of print March 25, 2019.

Address for reprints: Pavan Atluri, MD, Division of Cardiovascular Surgery Hospital at the University of Pennsylvania, 3400 Spruce St, 6 Silverstein, Philadelphia, PA 19104 (E-mail: Pavan.atluri@uphs.upenn.edu). J Thorac Cardiovasc Surg 2020;159:e209-10

$0022-5223 / \$ 36.00$

Copyright (c) 2019 by The American Association for Thoracic Surgery

https://doi.org/10.1016/j.jtcvs.2019.02.064
}

In this issue of the Journal, Yoshida and colleagues ${ }^{1}$ present their results of a computational fluid dynamic (CFD) model in a 40-year-old woman after HeartMate II (Abbott Cardiovascular-St Paul, St Paul, Minn) left ventricular assist device (LVAD) placement with a closed aortic valve. Their CFD was developed with computed tomography and accurate pressure assessments obtained through invasive measurement. They demonstrate turbulent, retrograde flow in the aortic root from the outflow cannula, with low shear stress at the aortic valve aside from focal intensities at the valve commissures. Yoshida and colleagues ${ }^{1}$ surmise that their model may bring insight into the development of aortic insufficiency (AI), a late complication increasingly appreciated in patients with LVADs after prolonged support. Significant regurgitant flow across the aortic valve leads to recirculation through the LVAD circuit and can result in poor end-organ perfusion. Exact mechanisms of AI development are incompletely understood, although increased prevalence with continuous-flow devices has suggested an underlying mechanical etiology. ${ }^{2}$

Grasping the complex flow patterns of viscous fluids subject to a variety of forces in vivo is difficult and influenced by a seemingly endless list of variables. CFD modeling-which, on a basic level, uses computational methods to solve the Navier-Stokes equations throughout prespecified boundary conditions - allows for sophisticated visualization of flow throughout a space and estimation of exerted forces. CFDs have long been used in the bioengineering space, but they are now increasingly being applied to clinical situations. CFD modeling is an elegant way to assess flow patterns with LVADs mathematically and to craft hypotheses about the impact of these forces in an educated manner.

Previously, the altered flow patterns with continuousflow devices have been directly associated with thinning of the ascending aortic wall. ${ }^{3}$ With increasingly granular detail, several groups have also demonstrated the importance of the outflow graft anastomosis location and angle in the shear stress and flow patterns at the root and

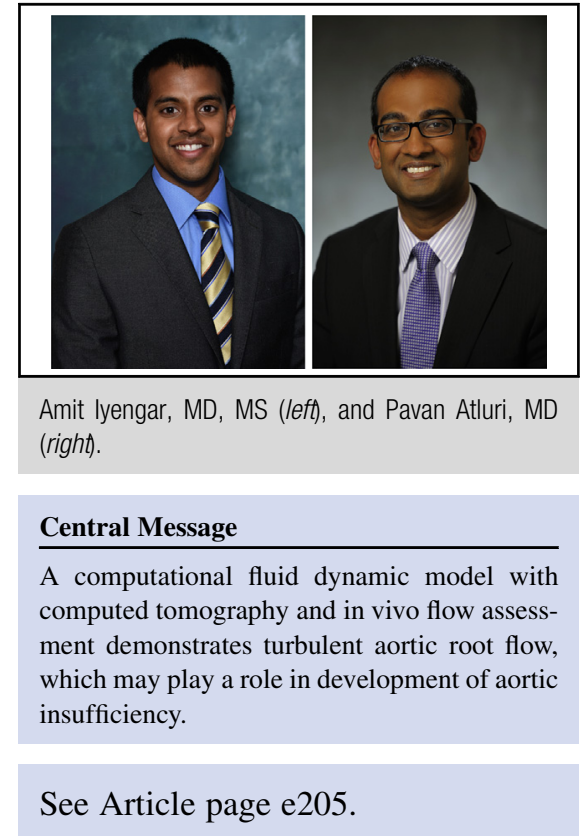

valve. ${ }^{4-7}$ The study of Yoshida and colleagues ${ }^{1}$ adds to the sophistication of these models by using and integrating measured pressure information. Taken together, a possible hypothesis for the development of AI may be thinning of the aortic wall and leaflets in the setting of low shear stress and turbulent flow, combined with some alterations at the commissures, noted to have slightly increased stress in the study of Yoshida and colleagues. ${ }^{1}$ What remains to be seen is a convincing causal link, by which altering these flow patterns alters the course of AI development in these patients. Continued thorough documentation of the complex forces at play will provide an increasingly educated mechanistic hypothesis.

Ultimately, with careful understanding of their implications, application of these techniques in the future may allow prediction of the ideal implantation geometry according individualized patient anatomy and may inform the surgeon before implantation of the ideal outflow graft position to minimize the risk of AI. In the future, these techniques promise a map informed by our knowledge of physics and fluid dynamics.

\section{References}

1. Yoshida S, Toda K, Miyagawa S, Sawa Y. Computational fluid dynamics visualizes turbulent flow in the aortic root of a patient under continuous-flow 
left ventricular assist device support. J Thorac Cardiovasc Surg. 2020;159: e205-7.

2. Cowger J, Pagani FD, Haft JW, Romano MA, Aaronson KD, Kolias TJ. The development of aortic insufficiency in left ventricular assist device-supported patients. Circ Heart Fail. 2010;3:668-74.

3. Nishimura T, Tatsumi E, Takaichi S, Taenaka Y, Wakisaka Y, Nakatani T, et al. Morphologic changes of the aortic wall due to reduced systemic pulse pressure in prolonged non pulsatile left heart bypass. ASAIO J. 1997;43:M691-5.

4. Karmonik C, Partovi S, Loebe M, Schmack B, Weymann A, Lumsden AB, et al. Computational fluid dynamics in patients with continuous-flow left ventricular assist device support show hemodynamic alterations in the ascending aorta. $J$ Thorac Cardiovasc Surg. 2014;147:1326-31.e1.
5. May-Newman K, Hillen B, Dembitsky W. Effect of left ventricular assist device outflow conduit anastomosis location on flow patterns in the native aorta. ASAIO J. 2006;52:132-9.

6. Caruso MV, Gramigna V, Rossi M, Serraino GF, Renzulli A, Fragomeni G. A computational fluid dynamics comparison between different outflow graft anastomosis locations of left ventricular assist device (LVAD) in a patient-specific aortic model. Int J Numer Method Biomed Eng. 2015;31.

7. Callington A, Long Q, Mohite P, Simon A, Mittal TK. Computational fluid dynamic study of hemodynamic effects on aortic root blood flow of systematically varied left ventricular assist device graft anastomosis design. J Thorac Cardiovasc Surg. 2015;150:696-704. 